Revised version

Organic Geochemistry 25, 263-265, 1996.

doi:10.1016/S0146-6380(96)00126-X

Correspondence: Dr. Eric Lichtfouse, INRA-CMSE-PME, 17, rue Sully, 21000 Dijon, France

Eric.Lichtfouse@dijon.inra.fr

\title{
Resistant ultralaminae in soils
}

\author{
ÉRIC LICHTFOUSE ${ }^{1,2}$, CLAIRE CHENU ${ }^{3}$ and FRANÇOIS BAUDIN ${ }^{4}$ \\ ${ }^{1}$ Laboratoire de Biogéochimie Isotopique associé à l'Institut National de la Recherche Agronomique (I.N.R.A.), \\ Université Pierre et Marie Curie, 75252 Paris Cx 05, \\ ${ }^{2}$ Present address : Laboratoire Sols et Environnement associé à l'I.N.R.A., École Nationale Supérieure d'Agronomie \\ et des Industries Alimentaires, Institut National Polytechnique de Lorraine, \\ 2 av. Forêt de Haye, 54505 Vandoeuvre-lès-Nancy, \\ ${ }^{3}$ Unité de Science du Sol, Institut National de la Recherche Agronomique, 78026 Versailles Cx, and ${ }^{4}$ Laboratoire de \\ Stratigraphie associé au Centre National de la Recherche Scientifique (URA 1761), Université Pierre et Marie Curie, \\ Boîte 117, 75252 Paris Cx 05, France.
}

\begin{abstract}
Observation of a chemically resistant organic residue from maize crop soils by transmission electron microscopy reveals the occurrence of thin laminae with 10-50 $\mathrm{nm}$ thickness, similar to resistant, highly aliphatic biopolymers found in kerogens and microbes. This discovery shows evidence for a novel and alternative mode of formation of soil organic matter by selective preservation of resistant biopolymers from soil microbes, in addition to the classical recondensation pathway proposed by the French chemist Maillard in 1917.
\end{abstract}

Key words - soil biopolymer, transmission electron microscopy.

\section{INTRODUCTION}

Soil organic matter is one of the major pool of carbon on Earth. It has a key position in the global carbon cycle, for instance as a sink of atmospheric $\mathrm{CO}_{2}$ and a source of sedimentary debris. The main part of soil organic matter is composed of complex, partly macromolecular, brown-yellow components called humic substances (Schnitzer, 1991). The precise biological origin, mode of formation and transformation of humic substances are so far poorly understood. As early as 1917, when he observed similar elemental compositions of natural humic substances and of condensation products of sugars and amino acids, the French chemist Maillard postulated that natural humic substances could be formed by recondensation of small molecules. More recently, numerous investigations in sediments have shown the existence of an alternative pathway of formation of sedimentary organic matter via selective preservation of resistant biopolymers (Tegelaar et al., 1989, Largeau et al., 1990, Derenne et al., 1991). In a study of forest profiles, Kögel-Knabner et al. (1992) further suggested that aliphatic biopolymers appear to be selectively preserved with increassing depth. Moreover, we have shown recently on isotopic grounds that the bulk of crop organic matter must be formed in situ, either by selective preservation of resistant biopolymers from soil microbes or by recondensation of small molecules from exudates and degradation products (Lichtfouse et al., 1995). Here, we provide microscopic evidence for the occurrence of resistant biopolymers in soil. 


\section{RESULTS AND DISCUSSION}

A soil sample (290 g, $0.97 \%$ of organic C) cropped 23 years with maize was thoroughly extracted with $\mathrm{CHCl}_{3}-\mathrm{MeOH} 3 / 1 \mathrm{v} / \mathrm{v}(3 \mathrm{x})$ to remove free lipids, then with $\mathrm{NaOH} 0.1 \mathrm{M}$ to remove humic and fulvic acids. The residue (humin and minerals) was then treated for classical kerogen extraction : $24 \mathrm{~h}$. with $1050 \mathrm{ml} \mathrm{HF}(48 \%) / 700 \mathrm{ml} \mathrm{HCl}$ (36\%), $24 \mathrm{~h}$. with $700 \mathrm{ml} \mathrm{HF}, 24 \mathrm{~h}$. with $700 \mathrm{ml} \mathrm{HCl}$, and then washed with $\mathrm{H}_{2} \mathrm{O}$ to $\mathrm{pH}$ 6 to yield $3.9 \mathrm{~g}$ of residue. The removal of main soil silicates and $\mathrm{Fe}$ minerals by acid hydrolysis was checked by the very low abundance of $\mathrm{Si}$ and $\mathrm{Fe}$ relative to $\mathrm{C}$ and $\mathrm{O}$ by $\mathrm{X}$-Ray diffraction. Elemental analysis gave $31 \%$ of C, $3 \%$ of $\mathrm{H}, 2.5 \%$ of $\mathrm{N}$ and $40 \%$ of uncombusted matter. Several attempts to reduce the uncombusted matter content by further drastic acid hydrolysis $(\mathrm{HCl} 36 \%$, reflux 48 h.) resulted in the total degradation/solubilization of organic C, as observed by Schulten and Schnitzer for humic acids (1993). An other attempt to perform a strong alkaline hydrolysis (KOH$\mathrm{MeOH} 5 \mathrm{M}$, reflux $24 \mathrm{~h}$.) gave similar results. The residue obtained by our procedure thus represents the most chemically resistant carbon pool that can be isolated in substantial amounts from a soil. The residue was embedded in epoxy resin, sliced in ultrathin sections, stained with $\mathrm{KMnO}_{4}$ then observed by transmission electron microscopy (TEM).

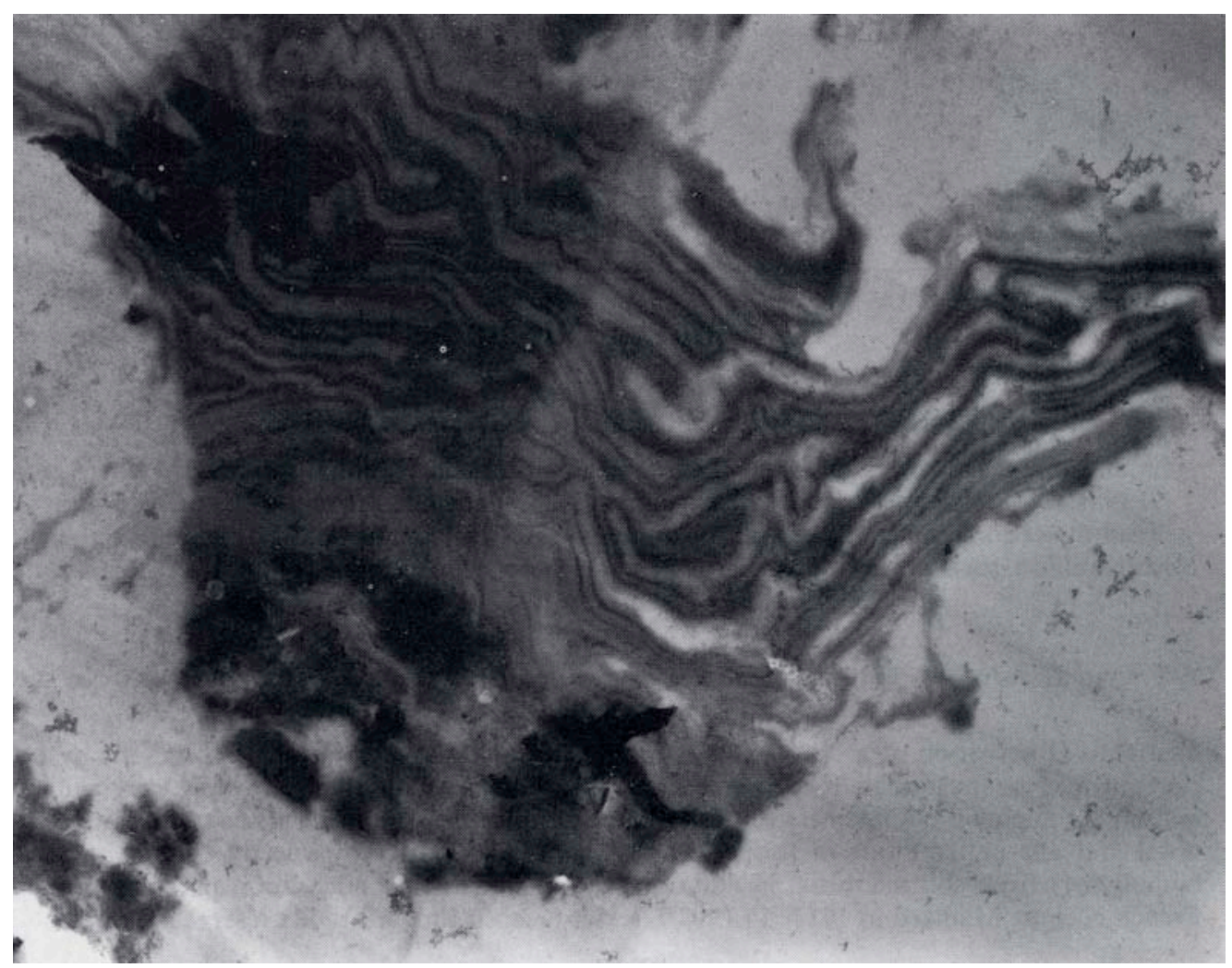

Figure 1. Transmission electron microscopy of a resistant residue, 'humin' or 'kerogen', from a maize crop soil, showing the occurrence of a resistant soil ultralaminae with thichnesses ranging from 10 to $50 \mathrm{~nm}(\mathrm{x}$ 17 000).

Observation of the soil residue by TEM showed a large contribution of amorphous organic matter, estimated to more than $60 \%$, along with recognizable wall debris either from plants or fungi $(0.2-2 \mu \mathrm{m}$ thickness). In addition, very thin laminae were observed as shown on Figure 1. Laminae were 10 to $50 \mathrm{~nm}$ thick and few $\mu \mathrm{m}$ long. They were composed of dark and light alternate zones, strongly then weakly 
$\mathrm{KMnO}_{4}$-stained, respectively. Since $\mathrm{KMnO}_{4}$ reacts rather specifically with unsaturated molecules such as aromatic rings from lignin debris (Ruel et al., 1984), the light zones are enriched in saturated carbon. A major part of this soil ultralaminae is therefore composed of saturated carbon.

These morphological features are very similar to very thin resistant walls that have been recently discovered in various microbes and sediments, and termed 'ultralaminae' (Largeau et al., 1990, Derenne et al., 1991). Recognition of resistant ultralaminae in soils imply that the formation and subsequent stabilization of soil organic carbon is not only performed by the classical recondensation of small molecules such as amino acids and carbohydrates (Maillard, 1917), but also by selective preservation of resistant biopolymers from soil microorganisms. Further structural elucidation studies of these novel components are in progress.

\section{REFERENCES}

Derenne S., Largeau C., Casadevall E., Berkaloff C. and Rousseau B. (1991) Chemical evidence of kerogen formation in source rocks and oil shales via selective preservation of thin resistant outer walls of microalgae : origin of ultralaminae. Geochim. Cosmochim. Acta 55, 1041-1050.

Kögel-Knabner I., De Leeuw J. W. and Hatcher P. G. (1992) Nature and distribution of alkyl carbon in forest soil profiles : implications for the origin and humification of aliphatic biomacromolecules. Sci. Total Environ. 117/118, 175-185.

Largeau C., Derenne S., Casadevall E., Berkaloff C., Corolleur M., Lugardon B., Raynaud J. F. and Connan J. (1990) Occurrence and origin of "ultralaminar" structures in "amorphous" kerogens of various source rocks and oil shales. Org. Geochem. 16, 889-895.

Lichtfouse É., Dou S., Girardin C., Grably M., Balesdent J., Behar F. and Vandenbroucke M. (1995) Unexpected ${ }^{13} \mathrm{C}$-enrichment of organic components from wheat crop soils : evidence for the in situ origin of soil organic matter. Org.

Geochem. 23, 865-868.

Maillard L. C. (1917) Identité des matières humiques de synthèse avec les matières humiques naturelles. Ann. Chimie (Paris) 7, 113-152.

Ruel K., Barnoud F. and Erikson K. E. (1984) Ultrastructural aspects of wood degradation by Sporotrichum pulverulentum. Observation on spruce wood impregnated with glucose. Holzforschung 38, 61-68.

Schnitzer M. (1991) Soil organic matter. The next 75 years. Soil Science 151, 41-58.

Schulten H.-R. and Schnitzer M. (1993) Temperature-resolved in-source pyrolysis-soft ionization mass spectrometry of soil humic acids. Org. Geochem. 20, 17-25.

Tegelaar E. W., De Leeuw J. W., Derenne S. and Largeau C. (1989) A reappraisal of kerogen formation. Geochim. Cosmochim. Acta 53, 3103-3106. 